\title{
A construção de saúde, entre o servir e a servidão: das relações entre servidores de um hospital psiquiátrico público
}

\author{
Cláudia de Negreiros Magnus ${ }^{1}$ e Álvaro Roberto Crespo Merlo ${ }^{2}$ \\ Universidade Federal do Rio Grande do Sul, Instituto de Psicologia, \\ Programa de Pós-Graduação em Psicologia Social e Institucional (Porto Alegre, RS)
}

\begin{abstract}
Este artigo apresenta um recorte da dissertação de mestrado cujo objetivo foi compreender a dinâmica do trabalho de profissionais de saúde mental de um hospital psiquiátrico público do estado do Rio Grande do Sul. O estudo aponta a forma danosa como o trabalho está organizado nesta instituição e suas implicações em relação à subjetividade, refletindo intensamente nas relações de trabalho entre os servidores. $\mathrm{O}$ aporte metodológico utilizado foi o da psicodinâmica do trabalho. As evidências foram obtidas por meio das falas do coletivo dos servidores proveniente de duas unidades de internação de pacientes agudos, constituídas por usuários de crack. Os servidores apontam como principal fator de sofrimento no trabalho a qualidade das relações entre colegas. Nas conclusões, ressalta-se a importância de espaços de discussão na instituição e do reconhecimento para a mobilização subjetiva, o que possibilitaria à rede coletiva desafiar a sua organização, operando assim intervenções contra servidão e a favor da construção da saúde.
\end{abstract}

Palavras-chave: Servidor, Relações de Trabalho, Psicodinâmica do Trabalho, Construção de saúde.

The construction of health, between serving and servitude: relations between servers in a public psychiatric hospital

This article presents part of the dissertation research with the objective of understanding the dynamics of the work of mental health professionals in a public psychiatric hospital in the state of Rio Grande do Sul. The study shows how damaging the work is managed in this institution and its implications in relation to subjectivity, reflecting intensely in working relationships between the servers. The methodological approach used was the psychodynamics of work. The evidence was obtained through interviews with servers from two units for acute patients (crack addicts). They indicate the quality of relationships between colleagues as the main drawback at work. In conclusion, the importance of opportunities for discussion within the institution and of recognizing subjective mobilization is emphasized, which would allow the network of servers to challenge their organization, thus acting against servitude and in favor of the construction of health.

Keywords: Server, Labor Relations, Psychodynamics of Work, Construction of Health.

\section{Introdução}

\begin{abstract}
pesquisa feita com o coletivo de servidores públicos estaduais do Hospital Psiquiátrico ISão Pedro (HPSP), no Rio Grande do Sul, para a construção da dissertação de mestrado Sob o peso dos grilhões: um estudo sobre a psicodinâmica do trabalho em um hospital psiquiátrico público (Magnus, 2009), abordou tanto a realidade do serviço público quanto a do trabalho desses servidores. Este artigo é um recorte do estudo e considera os dados relacionados à forma como o trabalho está organizado e que impactam diretamente na subjetividade e nas relações de trabalho dos servidores.
\end{abstract}

\footnotetext{
1 Doutoranda e Mestre em Psicologia Social e Institucional, Universidade Federal do Rio Grande do Sul, Instituto de Psicologia, Programa de Pós-Graduação em Psicologia Social e Institucional. Psicóloga do Trabalho na Secretaria Estadual de Saúde.

2 Médico do Trabalho, docente da Faculdade de Medicina, do Programa de Pós-Graduação em Psicologia Social e Institucional e Coordenador do Laboratório de Psicodinâmica do Trabalho da Universidade Federal do Rio Grande do Sul.
} 
A metodologia adotada foi a da psicodinâmica do trabalho, e, por coerência, a abordagem foi de caráter qualitativo, o que permitiu entender as implicações dos processos e das relações de trabalho da instituição escolhida, marcada tanto pelas características da esfera do serviço público quanto pela "loucura" que a habita.

O intuito da pesquisa foi problematizar questões que, rotineiramente, fazem os servidores sofrer no trabalho e compreender um pouco mais o funcionalismo, não apenas pela ótica do bônus próprio do serviço público, mas também seus ônus, marcados fortemente pela organização do trabalho pauperizada.

A reflexão dessas questões acentuadas por sua complexidade no contexto da esfera pública e, em particular, na área da saúde não é a da vitimização. Esta perspectiva desacreditaria toda a potência de mudança contida no coletivo de trabalhadores e o levaria a paralisação, ainda mais doentia. Ao contrário, o que se quer [a]firmar é que é possível, pela mobilização subjetiva, fomentar o reconhecimento e a construção de um significado para o trabalho que proporcione mais prazer aos servidores e que viabilize saúde a quem trata da saúde.

Neste sentido, o estudo constatou a existência de grilhões que exacerbam o sofrimento no trabalho, como o "peso" da loucura, os atravessamentos políticos, o sucateamento dos recursos, as condições e a forma de organização do trabalho propriamente dito e a precariedade dos vínculos relacionais entre servidores e usuários, entre servidores e suas chefias e entre colegas servidores. São estes em particular que se quer enfatizar neste artigo.

\section{A organização do trabalho na contemporaneidade}

O capitalismo imprime uma perda progressiva do controle do trabalhador sobre o processo produtivo e, consequentemente, sobre seu trabalho. Este fenômeno da perda de controle incide fortemente na subjetividade e, ao mesmo tempo, no coletivo de trabalho, considerando que a dinâmica do controle tanto é exercida sobre o trabalhador quanto este exerce sobre si mesmo na realização de suas atividades laborais.

Conforme Seligmann-Silva (1994), surgem cada vez mais formas sofisticadas de controle nos processos de trabalho, reveladas, por exemplo, no uso dos próprios equipamentos comuns, nas manifestações psicológicas de insegurança. Estas, muitas vezes, assumindo intensidade tal, dão lugar, inclusive, à sensação de estar sendo perseguido. A ansiedade vinculada a essas formas de controle pode tanto intensificar a tensão da fadiga mental quanto ocasionar inadequação das respostas em situações de emergência.

O mais impressionante, segundo a autora, é que o dispositivo que funciona como uma espécie de "controlador invisível" muitas vezes não é identificado pelos trabalhadores imediatamente, o que torna a vivência de estar sendo vigiado, particularmente, inquietante.

Outro elemento da contemporaneidade, segundo Castel (1998), é como vive a sociedade, cada vez mais uma sociedade de indivíduos em processo de individualização de massa. $\mathrm{Na}$ esfera do trabalho, a individualização das tarefas permite que apenas alguns escapem das sujeições coletivas e expressem melhor sua identidade. Segue o autor afirmando que, para a maioria dos trabalhadores, talvez signifique segmentação e fragmentação de tarefas, precariedade, isolamento e perda de proteções.

Por outra parte, há uma crise político-econômica global de empregabilidade, em que se destacam taxas crescentes e expressivas de desemprego, com excesso de pessoas demandando trabalho e pouca oferta de vagas. 
Dados oficiais corroboram esta realidade. Segundo a Organização Internacional do Trabalho $(2009,2011,2012)$, aproximadamente 20 milhões de postos de trabalho foram cortados em 2008, e outros 50 milhões tiveram o mesmo destino em 2009, sendo que em 2010 mais 20 milhões de postos de trabalho foram igualmente perdidos. Em 2012, a OIT declarou que não há recuperação à vista para os mercados de trabalho no mundo, uma vez que continuam faltando 50 milhões de empregos em nível mundial, e isso, inclusive, agudiza a problemática do emprego.

Desta forma, neste contexto de sociedade cada vez mais volátil, desigual e insegura, marcada, em particular, por altos índices de desemprego, ingressar no serviço público significa não só a entrada, mas a permanência vitalícia no universo de trabalho, com garantia de segurança e benefícios inerentes.

\section{Ser servidor no segmento do serviço público}

Ao se desmembrar, "servi-dor", aquele que serve à dor, a sonoridade do trocadilho presta-se, de alguma forma, à reflexão sobre a introjeção depreciativa do trabalho nas instituições públicas, marcado pelo sofrimento decorrente das condições e da forma de sua organização laboral em particular.

Conforme o dicionário Houaiss (2001, p. 2559), a origem etimológica da palavra "servidor" é "servitor", isto é, servo ou servidor dos deuses. O servidor é "aquele que serve; servente... indivíduo, remunerado ou não pelos cofres públicos, que exerce, temporariamente ou em caráter efetivo, cargo ou função pública, quer pertença ou não ao quadro do funcionalismo".

Fazem parte do ser servidor, então, de alguma forma, além dos elementos citados, a marcada subalternidade, o assalariamento e o uso mecanizado de rotinas nas tarefas cotidianas no trabalho público, aproximando-o da condição de operário. Segundo Ribeiro (2009), isto é perceptível no funcionalismo em todos os poderes, executivo, legislativo e judiciário.

Mesmo que o trabalho público tenha se modificado com as transformações do próprio Estado, ideologicamente persiste uma cultura entranhada e hierárquica de subalternidade, que impede a apropriação de direitos trabalhistas para os estratos situados nos escalões mais baixos da hierarquia e que privilegia benesses diferenciadas àqueles dos escalões superiores.

Ressalta ainda o autor que, não obstante as profundas transformações materiais nas relações de trabalho pós-escravidão, persiste muito dessa ideologia e dessas práticas anteriores, de servidão e opressão, dentro do Estado brasileiro. Para Ribeiro (2009), a prática demonstra resquícios das relações sociais e de trabalho do regime de escravidão e serventia, que, vindo do campo e incorporado ao processo de industrialização do país, permaneceu, condicionando a organização do trabalho até os dias de hoje.

Ribeiro (2009) reconhece que a ideologia e práticas retrógradas do serviço público manifestam-se no exercício autoritário de servidores em funções privilegiadas, hierarquicamente superiores, sobre aqueles em funções subalternas. $\mathrm{O}$ autoritarismo, além de ser, muitas vezes, aceito como natural e legítimo, é reproduzido para fora, ou seja, sobre a população a servir. Portanto, o autoritarismo e o maltrato interno e externo, históricos e ideológicos do Estado, são as causas também da dificuldade de acesso, insuficiência e ineficiência dos serviços públicos. Por essa razão, os serviços prestados à população como direitos de cidadania, dentre eles a saúde, continuam sendo percebidos e realizados como favores. 
No entanto, a possibilidade de tornar-se um funcionário público mobiliza o imaginário coletivo das pessoas no sentido de acionar desejos de estabilidade no trabalho e de aposentadoria garantida, direitos legítimos de todo trabalhador. Não é por acaso que se constata, cada vez mais, a procura crescente por concursos públicos. Mesmo que a realidade do serviço público inclua um cotidiano difícil para a maioria de seus servidores, ele é pouco explicitado e discutido. Há problemas complexos na operacionalização do trabalho que emperram, dificultando ou desqualificando a vida laboral em relação a si próprio, ao coletivo dos servidores e ao usuário do serviço.

As instituições públicas têm valores e dinâmica de trabalho próprios, produzindo formas de subjetivação particulares, ainda que todo trabalho, independentemente de sua gestão ser pública ou privada, por si só, propicie situações de prazer e também situações danosas à saúde física e emocional do trabalhador. Conforme Seligmann-Silva (1994), no caso do serviço público, ressalta-se que cada servidor deve, por sua conta e risco, aprender e realizar seu serviço da forma que lhe é possível, pois existem poucas diretrizes específicas para o trabalho, ou seja, há pouco trabalho prescrito e, havendo, em sua maioria é restrito ou desatualizado.

Outro atravessamento no cotidiano do servidor público é a questão política. Em várias situações, a interferência de gestores políticos inviabiliza a concretização de projetos legítimos, planejados e desenvolvidos pelos próprios servidores, consideradas as especificidades da instituição, pelo pouco apoio aos processos de trabalho ou por ignorarem seu funcionamento. Ainda na perspectiva desse atravessamento, constata-se que há gestores que assumem cargos estratégicos sem conhecimento e/ou capacidade técnica para tal e, ainda, desconhecem ou não concordam com as diretrizes fundamentais e estabelecidas pelos Ministérios ou Secretarias de Estado.

Há muitos gestores que não têm preocupação em dar sequência aos projetos de outros governos. Parece haver, entre muitos deles, o desejo de deixar "marca" própria. Desta forma, muitas mudanças ocorrem, não apenas a cada troca de governo municipal ou estadual, de dois em dois anos, mas também a qualquer momento, de acordo com a motivação política do gestor, ainda que fiquem inacabados projetos peculiares e interessantes à própria instituição, aos usuários e, muitas vezes, aos próprios servidores.

Várias decisões são emperradas em processos burocráticos que perdem, com frequência, o prazo de validade ou sua razão prescreve de existir. Quando tomadas, ocorrem, geralmente, de forma verticalizada, permeando vários níveis hierárquicos, com pouco respeito, diálogo e autonomia. Pelo excesso de chefias, coordenações e direções, comumente há conflitos, numa luta de poder em que todos perdem.

O funcionamento do trabalho é vivido numa dinâmica de violência e agressividade. Há muitas chefias nos diversos níveis hierárquicos, que, muitas vezes, com pouca autonomia e comunicação, confundem as equipes com contraordens, permitindo um jogo declarado de desrespeito em que as relações assumem um caráter muito mais pessoal e pouco profissional, abrindo brechas à discrepância e aos acordos informais quanto à operacionalização do trabalho. Esta prática comum adiciona mais desgastes ao servidor, à medida que revela a mínima sistematização de diretrizes básicas de trabalho, o que exacerba e expõe as contradições institucionais.

O serviço público pode ser considerado uma das categorias mais atingidas ou que mais "sofrem" com as mudanças em seu funcionamento. Elas acontecem mesmo com dificuldades institucionais, culturais, profissionais e até pessoais. O que agrava sua execução, no entanto, é a forma desrespeitosa e o volume com que são impostas e exigidas aos servidores. Cabe frisar que ocorrem mudanças o tempo todo, a qualquer hora, de toda natureza, tornando a instituição vulnerável. Isto contradiz o estigma popular de que o serviço público não muda e de os servidores são contrários a mudanças. Uma prática que ocorre com frequência e com 
repercussão em seu funcionamento é o fato de a instituição permanecer acéfala em cargos fundamentais devido à demora na substituição política de um gestor.

Essas mudanças ocorrem a despeito das propostas em andamento. Em geral, as proposições são planejadas de cima para baixo, sem levar em conta a opinião dos protagonistas que as praticam no dia a dia. Em decorrência disso, as propostas, por vezes, não correspondem aos anseios nem às necessidades dos servidores, que são justamente os sujeitos que operacionalizam e exercem as práticas na instituição.

Um problema estrutural, dentre vários, constatado nos órgãos públicos é a crescente redução do quadro de pessoal, sem substituição efetiva, resultado de prolongadas licenças, de exonerações e de aposentadorias. Neste caso, segundo informações do Sindicato dos Técnicos Científicos do Estado do Rio Grande do Sul (SINTERGS) e do Sindicato dos Servidores Públicos do Estado do Rio Grande do Sul (SINDSEPERS), cerca de 60\% dos servidores sindicalizados estão aposentados, o que revela massiva redução do quadro funcional.

Soma-se a esta realidade o fato de que muitos candidatos ingressantes desistem, e outros solicitam realocação para outros serviços da saúde, situação que agrava ainda mais o funcionamento do trabalho, acumulado para os servidores que permanecem nas instituições.

Outro fator que exacerba essa realidade é a não recolocação de servidores, pela ausência de concursos ou sendo oferecidos com vagas insuficientes, que vão precarizando, muito, o quadro e propiciando o adoecimento daqueles que precisam assumir funções de outros profissionais. Esse contexto também gera desestímulo em situações de mobilização coletiva, uma vez que resulta em menos tempo disponível aos servidores atuantes devido ao acúmulo de deveres além daqueles pelos quais respondiam.

Ainda sobre a organização do trabalho dos servidores públicos, Castel (1998) afirma que o dispositivo da "liberdade de turnos" facilita a "despersonalização" e a fragmentação da comunicação e dos vínculos afetivos entre as pessoas, uma vez que as relações ficam mais limitadas em função dos desencontros de horários, dificultando a operacionalização e a qualificação do trabalho.

Para Ribeiro (2009), o processo de exacerbação do individualismo e do empobrecimento moral envolve, de modo geral, os trabalhadores e, em particular, os servidores do Estado. Neste contexto, experimentam diversas emoções: medo em relação a questões de perdas materiais, de poder e de privilégios; rancor pelas condições de trabalho no sucateamento de recursos de toda ordem; ressentimento pelos colegas que compartilham do conservadorismo ideológico e de práticas antissociais. E se há preconceito do servidor para com o usuário, também ocorrem fortemente, por parte da sociedade, desvalorização e depreciação do servidor público. O cenário, segundo o autor, aponta para a necessidade de mudanças imediatas, a começar pela transição da condição de servidor do Estado para o de trabalhador público com todas suas implicações legais.

\section{O servidor público e as relações de trabalho}

A dinâmica de funcionamento do serviço público e, especificamente, do Hospital Psiquiátrico São Pedro traz severos desgastes nas relações de trabalho, sejam elas com pacientes, com colegas de mesmo nível hierárquico ou com chefias.

Para Dejours (1992), relação de trabalho são todos os laços humanos criados pela organização do trabalho, tais como as relações com a hierarquia, com as chefias, com a supervisão e com os outros trabalhadores - as quais, muitas vezes, são desagradáveis e, até, insuportáveis. No entanto, frisa o autor, para que se possa viver com as mais diversas 
insatisfações produzidas pela vida em sociedade, é necessária a repressão de inúmeros desejos e gratificações.

Mendes (2008), ao abordar a contribuição do trabalho como relação social, afirma que os sujeitos não trabalham para si mesmos, mas pelos outros, isto é, chefes e colegas. A autora compreende ainda que essa relação de poder, que é também de gênero, classe social e status profissional, gera tensão por exigir uma convivência que pressupõe relações de dominação, caracterizando o trabalho não só como um modo de produzir, mas ainda como um modo de "viver junto".

O trabalho, então, sendo uma atividade social, é constituído de relações de dominação, demandando espaços de negociação. Esta condição está vinculada à convivência sustentada por regras e por uma direção que nem sempre é feita com a participação dos servidores e que, ao mesmo tempo, é condição de construção de saúde destes. Isso denota que os servidores precisam ter uma autonomia mínima de poder para usar sua inteligência prática e tornarem os processos de trabalho mais saudáveis.

Outra questão importante a ser destacada no HPSP é o desconhecimento dos processos de trabalho e a vulnerabilidade decorrente dessa falta, o que gera desconfiança, dificultando a construção de vínculos mais estruturados e maduros, algo que facilitaria uma identificação grupal. Com a ausência da força grupal, restam o individualismo e a utilização de "bodes expiatórios" para a catarse da culpa e dos erros comuns a qualquer forma de organização do trabalho.

Constata-se a ocorrência de perseguições nas relações, mudando apenas os atores. Se essa prática é recorrente, a questão que se coloca é: por que os próprios servidores permitem tipos diferentes de violência na forma de tratamento, já que, invariavelmente, todos são atingidos? Uma hipótese cogitada aponta para o individualismo decorrente da matriz capitalística, conforme expressão de Guattari e Rolnik (2005), que caracteriza nossa sociedade, reproduzindo-se, no campo do trabalho; além, é claro, da possível experiência individual perversa de um certo "alívio" por não mais se tratar de si, mas de um outro. Esta atitude favorece, então, a construção de uma não potência, resultando na paralisia de muitos, empobrecendo e paralisando o grupo de trabalho.

As muitas frustrações vividas pelo servidores, algumas delas apontadas anteriormente, promovem descrédito externo e interno do coletivo, com a tendência a se voltar, ainda mais, para o individual, reforçando o processo de sofrimento e adoecimento.

É preciso ressaltar que o campo de atuação do agenciamento capitalístico é o da subjetividade dos sujeitos, que, por si só, já é deveras complexo, não admitindo homogeneização universalizante e reducionista, mas comportando larga heterogeneidade.

Nesse aspecto, Guattari (1990) aponta que a produção maquínica de subjetividade pode levar tanto para o melhor quanto para o pior. Isso significa no trabalho, segundo seu pensamento, a possibilidade do melhorar por meio da criação e da invenção de novos universos de referência. Quanto ao pior, refere-se a passividade, acomodação e continuidade das práticas despersonalizantes, desagregadoras e fragmentadoras para a saúde mental dos trabalhadores de saúde e dos usuários do serviço, resultando na pouca autonomia dos sujeitos envolvidos, despotencializando a todos, inclusive as próprias instituições ao boicotar práticas reais de saúde, sua razão de existir.

Sugerem Dejours, Abdoucheli e Jayet (1994) que, muitas vezes, a desmobilização aparente dos trabalhadores não é devida, apenas, a uma "crise de civilização", nem a fatores gerais da sociedade, mas se refere a problemas concretos relacionados à organização do trabalho. Os autores pontuam que, em geral, enfatizam-se a rotina, o desânimo e a resignação em si mesma e quase nunca se fala a respeito do próprio trabalho como monótono e aborrecido, características, aliás, marcantes no serviço público. 
Lancman (2008) assinala que os pressupostos teóricos e as crenças sobre o próprio trabalho do servidor da saúde mental são desconsiderados, obrigando-os a se inserir num processo dissonante entre o que acreditam que devem fazer e o que, efetivamente, fazem; a rever posições e a trabalhar, não raras vezes, em desacordo com seus próprios valores ou com o que acreditam ser um trabalho de excelência ou digno, direcionado principalmente ao usuário. $\mathrm{O}$ atendimento nessas condições, acrescentando-se a falta de ampliação do quadro de recursos humanos e de uma expansão plena do conjunto de serviços previstos pela reforma psiquiátrica, condiciona o servidor público a exercer suas atividades com uma qualidade inferior àquela que ajuíza devida, colocando-o frente ao dilema de oferecer assistência de qualidade inferior ou não oferecer assistência nenhuma.

A autora afirma ainda que, embora com relações de maior estabilidade garantida no trabalho, os profissionais do setor público de saúde, em especial da saúde mental, estão expostos a outras formas de precarização do trabalho, como: oscilações políticas e de planejamento que geram descontinuidade de projetos em curso; alterações na qualidade e na quantidade da demanda pelos serviços ofertados; desorganização ou ausência de redes de apoio ou referência; mudanças na organização do trabalho ou na natureza das ações de atenção que se chocam com o sentido e as crenças que os trabalhadores têm em relação ao desenvolvimento do seu trabalho; oferta de serviços com uma qualidade aquém daquela considerada razoável pelas equipes de saúde.

\section{Relatos do coletivo de servidores do HPSP}

Em relação a segregação social, o trabalho em hospital psiquiátrico tem ocupado, ainda mais, um lugar nevrálgico, por todas as razões apresentadas até então.

O coletivo de servidores deste estudo é representado por uma ampla diversidade de profissões, incluindo enfermeiro, auxiliar e técnico de enfermagem, fisioterapeuta, psicólogo, assistente social e terapeuta ocupacional. São sujeitos de meia-idade, que exercem funções ligadas ao cuidado direto dos pacientes, no turno diurno, perfazendo o total de sete pessoas.

Ainda que não tenham sido sujeitos diretos da pesquisa, é importante frisar que, em outro ponto desse serviço, estão os usuários. Eles se presentificam frequentemente em suas dramáticas situações, com seus conflitos psiquiátricos, emocionais e sociais, exacerbados ainda mais pelo uso intenso do crack, assinalando um difícil processo de doença/saúde e de relações institucionais.

Nas duas unidades de internação de pacientes agudos (masculina e feminina), assim definidos pela instituição em que foi realizado este estudo, a hospitalização surge como uma necessidade passageira, como um refúgio para a desintoxicação, uma vez que o foco está centrado, na maioria dos casos, em drogadição, mais especificamente no crack, e não mais em patologias mentais. Nesse novo contexto, as dificuldades encontradas, tais como incidentes agressivos, recaídas e, por vezes, o próprio agravamento progressivo do quadro, são muito mais frequentes do que costumavam ser e denunciam o mau estado geral dos usuários a cada nova internação. Vale indicar que há diferentes conotações no uso dos termos "usuários" e "pacientes", muito em função do (des)crédito em relação à reforma psiquiátrica.

A instituição psiquiátrica, em toda sua complexidade, só pode ser compreendida para além do que é visível e mensurável. Desta forma, os relatos apresentados a seguir ilustram e dimensionam questões sobre as relações estabelecidas no trabalho sob o ponto de vista de seus agentes: o coletivo de servidores do HPSP. Neste ponto do percurso, cabe ressaltar que a 
pesquisa que originou este artigo foi avaliada pelo Comitê de Ética do Hospital Psiquiátrico São Pedro.

Os fracassos repetitivos em relação à continuidade do tratamento, após a agudização, fazem que os profissionais assistam à degradação física e psíquica dos pacientes.

U: Às vezes, tu vê uma guria bonita que se perdeu. A gente aposta, tu conversa, passa a fissura, elas ficam bem conscientes. Daqui a três ou quatro meses estão de volta, cada volta é pior, porque voltam mais enfraquecidas. Tu vê na equipe... o psiquiatra que não aposta, que desacredita... e como é que tu vai atender desacreditando na capacidade de inserção?

Ocorre, em algumas situações, uma forte identificação dos servidores com a história de vida dos pacientes, principalmente com os mais jovens:

S: Às vezes, eles (pacientes) pedem para falar com os pais que os maltrataram, os adultos muitas vezes batem em seus filhos. A gente fica com pena... eu apanhei muito quando era criança.

Y: Eu fico muito mexida com a gurizada jovem, porque a gente lembra dos filhos.

O coletivo, para lidar com o medo advindo da agressividade dos pacientes, aponta como alternativa o estreitamento dos vínculos com estes:

$\mathrm{X}$ : Com os pacientes, eu não tenho medo, porque procuro ter uma boa relação, e principalmente, claro, com seus familiares. Esta é a chave.

Fica evidente pela fala do grupo que quem está mais próximo do poder consegue com muito mais facilidade obter ganhos:

U: Eu não era amiga dela... quem é amigo do rei e da rainha consegue as coisas aqui.

Segundo os servidores, os enfrentamentos das situações alicerçadas na proteção política são improdutivos, pois geram retaliações e desgastes profissionais e pessoais:

Z: Se tu peitar, tu fica marcada. Essa situação não vai mudar, porque as pessoas têm costas quentes. Tem coisa de manejo com pacientes, de inadequação total. Esses colegas pipocam em diversos setores e, depois, vão para outras instituições. Te choca ainda, mas não muda com os anos.

U: Não dá para peitar. A questão é que muita gente questiona porque não se enfrenta... a colega te manda para a geladeira, freezer e incinerador... quanto menos falar aqui, melhor.

Fica marcada na instituição a distância entre o trabalho prescrito e o real, pois os servidores verbalizam que, se fossem seguir as regras ao "pé da letra", não conseguiriam dar conta do trabalho real.

V: Eu mostrei para a colega o horário do banho dos pacientes, das seis às oito da manhã, mas os colegas do turno não vão atrás deles como a gente faz, daí não adianta, porque eles não tomam banho sozinhos . Então quem não consegue fica sem.

U: A gente deveria anotar nos prontuários os procedimentos, mas eu acabo não fazendo porque às vezes os residentes carregam os prontuários.

A respeito das interações humanas na instituição, os servidores apontam que há colegas que se isolam, silenciam, compartilham menos e ajuízam:

Y: A gente se sente aliviada quando vê que o outro também sente. Só fala quem tem vida lá fora; os que não falam são amargos, duros.

Os superiores esperam determinado desempenho dos servidores sem conhecer, em sua maioria, as especificidades dos serviços e de seus desdobramentos:

Z: Nem sei se eles sabem o que a gente faz aqui... Eu sei que falam que a unidade é difícil... 
V: Como o diretor não passa para conhecer a unidade, eles não sabem direito o que se passa, e o que é pior: o que a gente passa... Imagina que eu conheci minha chefia por acaso, porque ela se perdeu aqui dentro!

O grupo aponta a dificuldade de convivência com os colegas de mesmo nível hierárquico como um dos maiores problemas no trabalho:

Z: Aqui tem um monte dessas pérolas ("colegas difíceis"). Conviver e trabalhar junto é difícil, mas eu penso no benefício para o paciente.

X: Às vezes, num impulso, a pessoa ("colega") vem para cima de ti com tudo e daí mete os pés pelas mãos. É bem difícil... e o pior peso ainda é ter que conviver com ele nos próximos "muitos anos". É dureza... é muito mais fácil trabalhar com o paciente.

O coletivo percebe a precariedade dos vínculos relacionais em que os conflitos transcendem a questão profissional e invadem o plano pessoal:

T: Eu não gosto dela, e ela não gosta de mim. A gente não pode se cruzar aqui, estraga meu dia, tenho vontade de passar com o carro por cima, levo para terapia, para me reeducar, mas é muito difícil ter que encarar, me dá nojo.

$\mathrm{U}$ : Isso aqui nunca vai funcionar $100 \%$, porque os problemas pessoais interferem demais no trabalho. É insuportável, a gente quase não consegue trabalhar... a gente gasta um tempo com isso!

Esta questão é tão nevrálgica na rotina dos servidores, que o coletivo verbaliza preferir alguém com menos saber técnico, mas com maior facilidade de convivência em grupo:

Y: A gente prefere menor conhecimento técnico, mas com bom humor... Porque o péssimo humor contagia a todos.

Z: Às vezes, tu investe no colega e te "quebra" também. Mas na vida amorosa também é assim, a gente vive se decepcionando.

Sinalizam também a percepção da existência de uma casta profissional que é "protegida" pela instituição:

U: Aqui é um cartel médico; com eles, nada acontece. Vão me ligar para ver se estamos na unidade. Para nós, tem controle, mas com eles nada acontece.

T: Aqui a classificação é primeiro os médicos e, depois, Deus, os anjos... (risadas). Por isso eu adoro juiz, porque eles mandam nos médicos!

Além da onipotência evidenciada nos vínculos frágeis, os servidores relatam que a violência e a degradação ocorrem em cascata na instituição:

T: Além de todo o sofrimento que a gente tem com os pacientes, tem isso!

Y: Aqui (na unidade) é a mesma coisa com esta colega. É contínuo; ela podendo pisar, ela pisa. Se já não bastasse a rotina difícil... Mas me incomoda mesmo quando ela maltrata as pessoas que gostam de mim... daí me pega e ela sabe disso.

Por outro lado, há movimentos de mobilização coletiva em busca da construção de relações mais saudáveis, mesmo que pontuais, entre o coletivo de servidores. Nesse sentido, relatam diferentes situações. profissional:

Há uma conscientização de que os conflitos poderiam ser solucionados de forma mais

Y: Tive uma situação bem chata com um colega anos atrás. Eu chorava, queria ir embora da unidade... comprei briga com a pessoa. Se fosse hoje, eu abriria uma sindicância, porque daí não pessoaliza tanto. 
Apesar das contradições, os servidores sinalizam o desejo por relações respeitosas com os colegas e ressaltam o prazer advindo de vínculos genuínos que se formam em algumas situações:

V: A nossa equipe é muito unida. Isso ajuda muito, dá forças, a gente se encontra fora daqui. É bom vir para cá atender, é prazeroso encontrar alguns colegas, reforça o grupo.

Em alguns momentos, ocorrem indícios de uma mobilização coletiva por melhores condições de trabalho e por maior suporte institucional em situações mais complexas.

U: Sabe o que a gente faz quando a coisa aperta? Primeiro, a gente tenta se respaldar entre a gente (unidade). A nossa equipe não tem atrito com os médicos. Num segundo momento, a divisão é por classe, mas a minha área é enfraquecida junto à direção... a força tá na gente mesmo.

T: Se a gente se unisse mais, conseguiríamos muito mais coisas aqui dentro. Eu não posso pensar só em mim. Pressionando em grupo a direção, eles se mexeriam mais.

$\mathrm{V}$ : A gente tem que ter esperanças. Alguma coisa vai ter que mudar, uma hora vai ter que mudar, do jeito que está não dá!

O reconhecimento de seu trabalho é percebido pelos servidores ao dizerem:

U: Os estagiários, quando vão embora, falam bem do trabalho que realizamos aqui. Já é um reconhecimento, né?

Z: Não sei se é só dos estagiários, a gente mesmo, enquanto colegas. Da direção, é mais complicado, tu escuta coisas que te enfurecem. A equipe estava trabalhando unida e tu ouve que não... então tem dos colegas, mas não da direção!

X: Poxa, vou dizer uma coisa (emocionada)... Não é porque eu tô na presença da $Z$, mas esta pessoa é iluminada, vale ouro (choram). Porque, quando eu mais precisava dela, ela me deu o maior apoio. Foi me visitar quando eu operei. Isso vale muito e apaga a imagem dos colegas ruins!

Os servidores apontam o reconhecimento por parte dos pacientes e familiares como um reforço positivo para o seu próprio trabalho:

T: Nós recebemos uma vez um agradecimento de uma mãe pelo tratamento do seu filho. Ela fez isso através de jornal, botaram um anúncio de agradecimento à equipe, com nossos nomes, foi muito legal (mostram depois o anúncio transformado em quadro na parede do posto de enfermagem).

Y: Ela (mãe) me pegou na porta e me agradeceu muito, chorou, disse que a gente se importava. Nossa, isso faz toda a diferença para gente! (emocionada)

As pequenas concretizações possíveis, mesmo quando operam no microestrutural, geram muito prazer aos servidores, porque estão relacionadas a um fazer diferente. Desta forma, mobilizam a identificação com o trabalho e a possibilidade de construção de novos significados:

Y: Me fortalece quando vejo os pacientes entrando muito mal e saindo bem. $70,80 \%$ dos pacientes não ficam bem porque não querem, ou não têm estrutura. Mas os que querem, os que têm desejo, a gente vê que o nosso trabalho dá resultado.

Em relação às estratégias coletivas de saúde, fica evidente a rede de ajuda construída pelo coletivo para criar condições mais favoráveis de trabalho:

T: Agora, na unidade, conseguimos nos unir e ganhamos bebedouros, ar-condicionado, mas daí estava parado porque não tinha quem fizesse a colocação. Fizemos um racha e pagamos nós, todo mundo colaborou um pouco. 
Y: A gente tem toalha, talheres que ficam aí para ajudar os colegas de outro turno. Como eu dei a tinta este mês para pintar as paredes, não vou ajudar no café. A gente joga... quando tem almoço na unidade, a gente já tá equipado, e assim vai. Uma mão lava a outra e todo mundo lava o rosto!

Surgem espaços coletivos organizados em função das festividades, com muita comida visando a integrar e fortalecer ainda mais o grupo de trabalho:

U: Ontem, a gente se inspirou e teve uma coisa diferente na unidade. A colega organizou um lanche coletivo, tinha tanta coisa... Nossa, foi tão legal. Já é um espaço diferente, em que tu conversa, troca. A gente não se sente sozinho!

Os espaços de fala genuínos e informais são valorizados pelo grupo, pois permitem a identificação entre os servidores, o que torna o trabalho mais ameno:

Z: Ah, poder dividir as angústias com os colegas é muito bom!

T: É, nestes encontros, a gente vê que não é só a gente, porque a gente fala com outros serviços, com outros colegas... todo mundo sofre um pouco.

A capacidade de elaborar o sofrimento por meio do humor neutraliza a ansiedade diante de situações difíceis:

Y: É, a questão do bom humor é fundamental para nós, porque mesmo na desgraça a gente ri, e olha que tem pacientes que gritam o tempo todo. Não é fácil!

Z: Sabe qual é a diferença entre psiquiatra e Deus? Deus sabe que não é psiquiatra! (risos)

U: Sabe o que meus filhos me dizem com frequência?: "Ué, mãe, deixaram tu sair do hospício hoje?" (risos).

\section{Conclusão}

Castel (1998) defende que o poder público é a única instância capaz de construir pontes entre os polos do individualismo e do coletivo, impondo um mínimo de coesão à sociedade. O recurso, segundo ele, seria um Estado estrategista que estendesse amplamente suas intervenções para acompanhar o processo de individualização, desarmando seus pontos de tensão e evitando suas rupturas. Haveria espaço para um Estado, até mesmo protetor, porque, numa sociedade hiperdiversificada e corroída pelo individualismo, "não existe coesão social sem proteção social".

Corroborando esta posição, Mendes (2003) defende que é na cotidianidade que se estabelecem as relações sociais de dominação e de reprodução, e é nela e a partir dela que o Estado moderno deveria assumir seu papel de gestor da sociedade, da micro à macro realidade. Para tanto, é importante investir no exercício de compreensão da cotidianidade em todas as suas dimensões, percebendo a relação existente entre o homem trabalhador e o mundo, entre sua singularidade e a totalidade político-social de seu cotidiano. Pois é nesse tempo-lugar que ocorrem as intensas inter-relações sociais desses sujeitos e de seus novos lugares políticos e, sem dúvida, a premência de uma nova prática de trabalho.

Ao descrever o momento atual das políticas públicas em saúde mental, Lancman (2008) descreve este período como o do "entre", da transição entre o antigo e o novo que está por ser construído. Tal processo de mudança constitui uma possibilidade importante para a contribuição dos servidores visando ao aprimoramento de um novo modelo que produza mais saúde a todos os atores envolvidos por meio de seu trabalho. 
Nesse aspecto, para Dejours (1999), o trabalho nunca é neutro em relação à subjetividade: ou ele contribui para construir a identidade e a saúde ou, ao contrário, construir a identidade e a doença, porque entende que todo o trabalho é vivido afetivamente por quem o faz.

Logo, a natureza, a qualidade e a dinâmica das relações no interior dos coletivos têm peso considerável, se não decisivo, nos efeitos de seu trabalho sobre a saúde. Conforme assinalam Barros e Filho (2007), promover saúde nos locais de trabalho é aprimorar a capacidade de compreender e analisar o trabalho e sua forma de organização. Nesse sentido, os servidores sinalizaram diferentes questões limitantes e, ao mesmo tempo, impulsoras à construção da saúde.

Os servidores percebem que, na prática, o recurso público, de modo geral, "não tem dono", ou é de todos e não é de ninguém. Para eles, é um indicativo de uso permissivo, uma dimensão de que tudo é possível, o que autoriza comportamentos não éticos e evidencia um alto índice de desrespeito pelo alheio. Referem-se a atitudes não apenas em relação ao patrimônio público, mas diluídas entre as relações.

Também reconhecem que, no momento em que surgem atos de sabotagem ou de violência entre si e entre eles e a hierarquia, o coletivo não funciona mais, desacreditando-se, e em consequência revela descomprometimento com as relações de trabalho e suas tarefas cotidianas, bem como com as relações entre si.

Considerando a definição de Foucault (1998) sobre relações de poder, entende-se que estas não estão numa classe dominante apenas, ou mesmo em um governo, mas em toda e qualquer relação entre humanos em que alguém tenta dirigir a conduta de outrem. Os servidores afirmam que a dinâmica das relações entre chefias e servidores, e mesmo entre eles, ocorre de forma truncada e insatisfatória.

De acordo com Dejours (1997), há mesmo uma defasagem entre as dimensões do trabalho prescrito e real, a qual só poderá ser gerida pelo engajamento da subjetividade dos trabalhadores. Esse engajamento recebe a denominação de "inteligência astuciosa" ou "prática", mobilizada frente ao real e que tem como característica fundamental a inventividade e a criatividade. Nesse mesmo sentido, assinalam Sznelwar e Abrahão (citados por Mendes et al., 2008) que os sujeitos elaboram estratégias operatórias para responder às exigências contidas na tarefa. Se a organização for rígida, não haverá espaço para modificações nas tarefas e nas relações com os colegas e com a hierarquia, encontrando-se assim bloqueios. Trabalhar sob essas condições traz graves consequências para a qualidade daquilo que se faz e para a subjetividade dos trabalhadores. Portanto, é importante salientar que a inserção do sujeito entre o trabalho prescrito e real é sempre conflitiva. Isso foi ressaltado pelos servidores ao reconhecerem que "enlouquece" tanto não ter um mínimo de prescrição quanto, tendo, não acatá-la.

Os servidores sentem-se destituídos da capacidade de planejar e executar seu trabalho, pois, ao não se apropriarem do processo laboral, perdem sua autonomia e são desqualificados quanto ao seu saber técnico. Importa, então, que a palavra circule, criando espaços legítimos para debates coletivos, que possibilitem a construção de vínculos sustentados por uma política interna de reconhecimento e, em decorrência, de cooperação.

Quanto ao reconhecimento, essencial para a psicodinâmica do trabalho, este permite, conforme Mendes et al. (2008), a ressignificação do sofrimento, mas não necessariamente sua transformação, pois esta passa pela ação dos trabalhadores na organização do trabalho, por meio fundamentalmente da cooperação e da política, que envolvem as dinâmicas subjetivas. $\mathrm{O}$ reconhecimento esperado pelo trabalhador, segundo Dejours (1999), é, em primeiro lugar, o dos colegas, que são os mais indicados para apreciar a qualidade dessa contribuição, e, em segundo lugar, deve relacionar-se a alguma utilidade econômica, social ou técnica das 
contribuições dos trabalhadores - neste caso, feito essencialmente pelos superiores hierárquicos. Os servidores confirmam essa perspectiva.

Para Dejours (1999), a organização do trabalho restringe-se a repartir tarefas, responsabilidades e atribuições, mas tem dificuldade, porque é da ordem do impossível, em prescrever a cooperação, uma vez que esta supõe que os diferentes parceiros construam acordos entre si. Assim, a partir desses acordos, passa-se a normativas e, destas, às novas formas de trabalho. Por isso, para o autor, são os próprios trabalhadores os mais indicados a encontrar soluções e oferecer sugestões para mudar efetivamente a organização do trabalho ao conseguirem entender melhor sua constituição. Logo, a grande aposta para a qualificação dos serviços e das relações de trabalho no HPSP é a mobilização subjetiva de seus trabalhadores, o que possibilitaria à rede coletiva desafiar sua organização, operando assim intervenções contra a servidão e a favor da construção da saúde.

\section{Referências}

Barros, M. E. B. \& Filho, S. B. S. (Orgs.). (2007). Trabalhador da saúde, muito prazer! Protagonismo dos trabalhadores na gestão do trabalho em saúde. Ijuí: Editora da Unijuí.

Castel, R. (1998). As metamorfoses da questão social. Petrópolis: Vozes.

Dejours, C. (1992). A loucura do trabalho: estudos de psicopatologia do trabalho (5a ed.). São Paulo: Cortez/Oboré.

Dejours, C., Abdoucheli, E., \& Jayet, C. (1994). Psicodinâmica do trabalho: contribuições da escola dejouriana à análise da relação prazer, sofrimento e trabalho (M. L. S. Betiol, coord.). São Paulo: Atlas.

Dejours, C. (1997). O fator humano. Rio de Janeiro: Fundação Getúlio Vargas.

Dejours, C. (1999). Conferências brasileiras: identidade, reconhecimento e transgressão no trabalho. São Paulo: Fundap.

Dejours, C. (2005). A banalização da injustiça social. Rio de Janeiro: Fundação Getúlio Vargas.

Foucault, M. (1998). Vigiar e punir: nascimento da prisão (18ª ed.). Petrópolis: Vozes.

Guattari, F. (1990). As três ecologias. Campinas: Papirus.

Guattari, F. \& Rolnik, S. (2005). Micropolítica: cartografias do desejo (7ª ed.). Petrópolis: Vozes.

Houaiss, A., Villar, M. D. S. \& Franco, F. M. M. (2001). Dicionário Houaiss da língua portuguesa. Rio de Janeiro: Objetiva.

Lancman, S. (org.). (2008). Políticas públicas e processos de trabalho em saúde mental. Brasília: Paralelo 15.

Magnus, C. N. (2009). Sob o peso dos grilhões: um estudo sobre a psicodinâmica do trabalho em um hospital psiquiátrico público. Dissertação de Mestrado, Instituto de Psicologia Social e Institucional, Universidade Federal do Rio Grande do Sul, Porto Alegre.

Mendes, J. M. R. (2003). O verso e o anverso de uma história: o acidente e a morte no trabalho. Porto Alegre: EDIPUCRS.

Mendes, A. M., Luque, A. G., Dejours, C., Karam, H., Calgaro, J. C. C., Alvaro, J. L. et al. (2008). Prazer, reconhecimento e transformação do sofrimento no trabalho. In M. Mendes (Org.), Trabalho e saúde: o sujeito entre emancipação e servidão (pp. 13-25). Curitiba: Juruá.

Sznelwar, L. V. \& Abrahão, J. I. (2008). Entre a tarefa e a atividade, a dor do trabalhar. In M. Mendes (Org.), Trabalho e saúde: o sujeito entre emancipação e servidão (pp. 102-114). Curitiba: Juruá.

OIT. Organização Internacional do Trabalho. Recuperado em 12 abril, 2009, de http://www.oitbrasil.org.br.

Política Nacional de Humanização (2009). Recuperado em 2 de fevereiro, 2009, de www.saude.gov.br/humanizasus.

Ribeiro, H. P. (2009). De servidor a trabalhador público. Recuperado em 5 de abril, 2009, de http://www.sinjusc.org.br/admin/uploads/baixar/Deservido\%20doestadoatrabalhadorpublicoreduzido.doc.

Seligmann-Silva, E. (1994). Uma história de "crise de nervos": saúde mental e trabalho. In J. T. Buschinelli, L. E. Rocha \& R. M. Rigotto (Orgs.), Isto é trabalho de gente? Vida, doença e trabalho no Brasil (pp. 609-635). Petrópolis: Vozes.

Secretaria da Saúde do Estado do Rio Grande do Sul (2009). Recuperado em outubro, 2007, de http://www.saude.rs.gov.br.

Sindicato dos Servidores Públicos do Rio Grande do Sul (SINDSEPE). (2009). Recuperado em 2 de fevereiro, 2009, de http://www.sindsepers.org.br/. 
Sindicato dos Técnico-Científicos do Rio Grande do Sul (SINTERGS). (2009). Recuperado em 2 de fevereiro, 2009, de http://www.sintergs.com.br/site/.

\section{Endereço para correspondência}

cmagnus@psicoonline.com.br, merlo@ufrgs.br

Recebido em: 18/05/2011

Revisado em: 28/05/2012

Aprovado em: 28/06/2012 